\title{
Radiochemical ageing of ethylene-propylene-diene elastomers. 4. Evaluation of some anti-oxidants
}

\author{
A. Rivaton, S. Cambon, J.-L. Gardette* \\ Laboratoire de Photochimie Moléculaire et Macromoléculaire, UMR CNRS-UBP 6505, Université Blaise Pascal \\ (Clermont-Ferrand), F-63177, Aubière Cedex, France
}

Received 31 January 2005; accepted 11 April 2005

Available online 12 July 2005

\begin{abstract}
The preceding papers of this series were devoted to the identification and quantification of the main chemical changes resulting from the radiochemical ageing of EPDM (77.9\% ethylene, $21.4 \%$ propylene, $0.7 \%$ diene) and EPR $(76.6 \%$ ethylene, $23.4 \%$ propylene) films irradiated under oxygen atmosphere using ${ }^{60} \mathrm{Co} \gamma$-rays. It was shown that two processes are involved in the EPDM radio-oxidation. The random $\gamma$-radiolysis of the polymer provides a constant source of macro-alkyl radicals that are likely to initiate a selective oxidation of the polymer through free-radicals reactions involving the abstraction of labile hydrogen atoms. In the present paper, infrared spectroscopy has been used to study the $\gamma$-degradation of EPDM cross-linked with dicumyl peroxide and/or stabilised with two types of anti-oxidants (hindered phenol or amine-type). The results show that the anti-oxidants are not efficient in preventing oxidation. To understand the lack of efficiency of the stabilisers, the impacts of the various formulations on the rate of degradation of EPDM against chain oxidation involved in thermal and UV ageing were also studied.
\end{abstract}

(C) 2005 Published by Elsevier Ltd.

Keywords: Radiochemical ageing; EPDM; Stabilisation; Radio-oxidation; Infrared spectroscopy

\section{Introduction}

The modifications of the structure and properties of polymers resulting from exposure to ionising radiation has attracted much interest. The present study, developed in a series of articles, concerns the radiative ageing of EPDM copolymers which are composed of ethylene (PE), propylene (PP) and diene monomer (5-ethylidene-2norbornene (ENB)). The aim is to propose mechanisms accounting for the main routes of EPDM degradation. Irradiations were carried out both in the presence and in the absence of oxygen, and the comparison with EPR containing the same ethylene/propylene ratio than

\footnotetext{
* Corresponding author. Tel.: +33 473407177; fax: + 33473407700 .

E-mail address: luc.gardette@univ-bpclermont.fr (J.-L. Gardette).
}

EPDM were made to assess the importance of the diene moiety and the involvement of oxygen.

The first paper focused on the modifications of the chemical structure of EPDM (77.9\% ethylene, $21.4 \%$ propylene, $0.7 \%$ diene) and EPR (76.6\% ethylene, $23.4 \%$ propylene) under argon atmosphere [1]. Irradiation of EPDM and EPR was shown to generate trans-vinylene, vinyl, vinylidene and diene unsaturation, with similar radiochemical yields for both polymers. Degradation was shown to also involve cross-linking and production of hydrogen. The presence of the diene, the double bonds of which are consumed with a high radiochemical yield, contributes to the increase in rate and intermolecular bridge density. Mechanisms were proposed to account for the main routes of EPDM degradation. In particular, it was shown that the depletion of unsaturation, which 
cannot result from unselective direct radiolysis, involves addition by macro-radicals formed in the EPDM radiolysis.

In paper 2 [2], the chemical changes occurring in EPDM and EPR films $\gamma$-irradiated under oxygen atmosphere were identified and quantified using a combination of IR analysis, derivatisation reactions and iodometric titration. The extent of cross-linking was evaluated by gel fraction methods.

On the basis of these experimental results, mechanisms accounting for EPDM $\gamma$-degradation under oxygen atmosphere were proposed in paper 3 [3]. Discussion took also into account complementary experimental results showing the instability of hydroperoxide groups under $\gamma$-radiation. It was shown that radio-oxidation involves two concomitant processes. As the interaction of high energy radiation with matter is unselective, the irradiation of EPDM (77.9\% ethylene) mainly involves $\mathrm{C}-\mathrm{H}$ bond scissions of the ethylene units. Radicals resulting from the direct effects of radiation are likely to initiate a chain oxidation process. It was shown that the methylene groups in an $\alpha$-position to the double bonds of the ENB are the most oxidisable site and that saturation reactions of the ENB moieties cause the cross-linking of EPDM films.

The present paper reports some recent results and obtained ion stabilisation of EPDM to radiochemical ageing. The EPDM samples were vulcanised with dicumyl peroxide and/or stabilised with hindered phenol or amine-type anti-oxidant. In order to verify the efficiency of the stabilisers against chain oxidation, the impact of the various formulations on the oxidation rate of EPDM induced by UV-light or by temperature was also studied.

Thermo-oxidation, photo-oxidation and $\gamma$-irradiation involve a chain-oxidation process whose common points can be described according to [4]:

$$
\begin{aligned}
& \text { initiation } \quad \mathrm{PH} \stackrel{(1)}{\longrightarrow} \mathrm{P}^{*} \\
& \text { propagation }\left\{\begin{array}{l}
\mathrm{P}^{*}+\mathrm{O}_{2} \stackrel{(2)}{\longrightarrow} \mathrm{PO}_{2}^{*} \\
\mathrm{PO}_{2}^{*}+\mathrm{PH} \stackrel{(3)}{\longrightarrow} \mathrm{PO}_{2} \mathrm{H}+\mathrm{P}^{*}
\end{array}\right. \\
& \text { termination } \mathrm{PO}_{2}^{\cdot}+\mathrm{PO}_{2}^{\cdot} \stackrel{(4)}{\longrightarrow} \text { inactive products }+\mathrm{O}_{2}
\end{aligned}
$$

The main differences between the processes lie in the initiation step and in the hydroperoxide decomposition. It is generally admitted that photo- and thermooxidation starts on the ENB moiety before reaching the ethylene-propylene units [5,6]. The thermal and photochemical degradation of hydroperoxides involves the scission of the $\mathrm{O}-\mathrm{O}$ bonds [7].

It is briefly recalled that anti-oxidants $(\mathrm{AH})$ prevent by chain transfer (i) or termination (ii) the propagation reactions [7] in any oxidation process (UV, thermal or radiation initiated), according to:

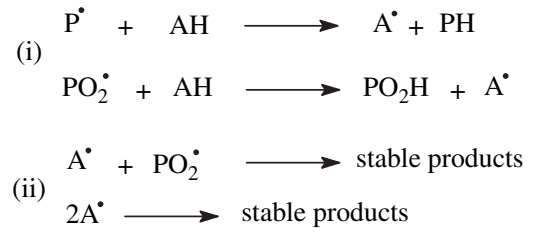

The present paper reports a study of the behaviour of various formulations under conditions of oxidation initiated by UV-light, temperature or $\gamma$-radiations. The objective is to compare the efficiency of the anti-oxidant in stabilising EPDM against these various conditions of degradation.

\section{Experimental}

Ethylene-propylene-diene monomer (EPDM), based on 5-ethylidene-2-norbornene (ENB), was supplied by Dupont under the trade name NORDEL IP 3725. The molar composition of EPDM determined by solid state ${ }^{13} \mathrm{C}$ NMR was $77.9 \%$ ethylene, $21.4 \%$ propylene, $0.7 \%$ diene. Various formulations of EPDM were processed: a pure gum (EPDM), an elastomer cross-linked agent with dicumyl peroxide (Aldrich) and an elastomer stabilised with two types of anti-oxidants: a hindered phenol (Irganox 1035, Ciba-Geigy) and an amine-type anti-oxidant (Vulkanox 4010 NA, Bayer). A detailed description of the samples is given in Table 1.
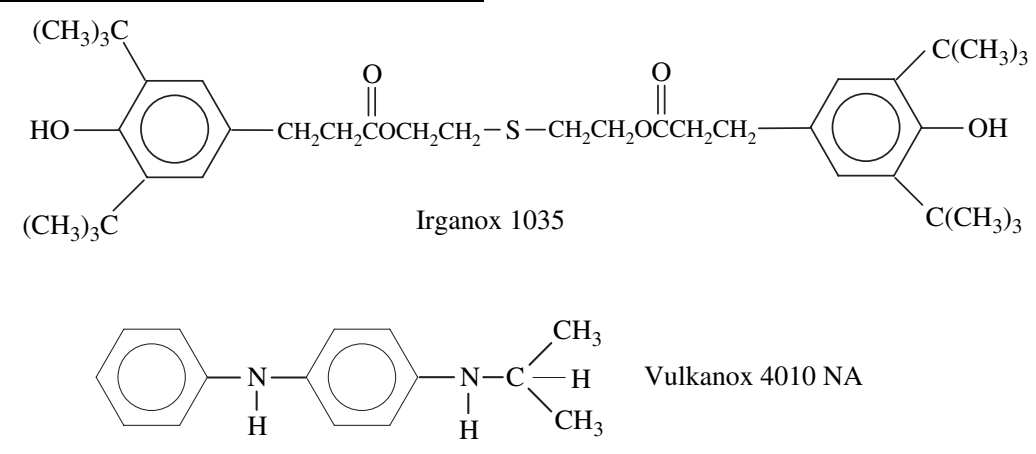
Table 1

Composition of the EPDM compounds

\begin{tabular}{clll}
\hline Sample code & $\begin{array}{l}\text { Cross-linking } \\
\text { agent }\end{array}$ & $\begin{array}{l}\text { Irganox 1035 } \\
\text { (phenolic AO) }\end{array}$ & $\begin{array}{l}\text { Vulkanox 4010 } \\
\text { NA (amine-type AO) }\end{array}$ \\
\hline Additive-free & - & - & - \\
$\quad$ EPDM 9 & & & \\
EPDM 9 & - & - & - \\
EPDM 10 & 3 & - & - \\
EPDM 11 & 3 & 0.1 & - \\
EPDM 12 & 3 & - & 1 \\
EPDM 13 & - & 0.1 & - \\
\hline
\end{tabular}

Concentrations are expressed in $\mathrm{wt} \%$.

All the EPDM samples contained processing antioxidants, which can be characterised by a UV absorption band at $280 \mathrm{~nm}$ with a shoulder around $230 \mathrm{~nm}$. The remaining processing anti-oxidants were removed from the pure gum (EPDM 9) by Soxhlet extraction with methanol for $24 \mathrm{~h}$. The sample was then vacuum dried for $24 \mathrm{~h}$. This sample, which contains no residual processing antioxidants, is referred as "additive-free EPDM 9" in Table 1.

EPDM films (approximately $100 \mu \mathrm{m}$ thickness) were prepared by compression moulding between PTFEcoated glass sheets at 200 bar in an electrically heated laboratory press at $180{ }^{\circ} \mathrm{C}$ for $10 \mathrm{~min}$. Films were then stored in a vacuum oven for $10 \mathrm{~min}$ at $100{ }^{\circ} \mathrm{C}$.

Radiochemical ageing was performed at Arc-Nucléart (CEA/Grenoble, France). Gamma irradiation was delivered by ${ }^{60} \mathrm{Co} \gamma$-sources. Samples were irradiated in a watertight container, at doses between 5 and $455 \mathrm{kGy}$, dose rate being $1 \mathrm{kGy} / \mathrm{h}$, with an oxygen flow of $0.5 \mathrm{~L} / \mathrm{min}$ at $20{ }^{\circ} \mathrm{C}$.

Thermal oxidation was performed at $100{ }^{\circ} \mathrm{C}$ in an oven ventilated by natural convection. Photo-oxidation was performed in a polychromatic set-up based on the conventional accelerating device SEPAP [8] but modified in such a way that photo-oxidation can be performed at $35^{\circ} \mathrm{C}$. The instrument already described [9] elsewhere contains only one medium pressure mercury lamp filtered with a borosilicate envelope (Mazda MA 400).

The changes in several typical functions and the decrease of the double bond content in EPDM were followed by infrared spectroscopy with a Nicolet MagnaIR 760 FTIR spectrophotometer (32 scans summation, nominal resolution of $4 \mathrm{~cm}^{-1}$ ). Changes in the UV-vis spectra were followed with a Shimadzu UV-2101PC spectrophotometer equipped with an integrating sphere.

Total peroxide species (hydroperoxides and peroxides) were titrated using the iodometric method $[10,11]$.

\section{Experimental results}

\subsection{Radio-oxidation}

Radio-oxidation of EPDM leads to notable modifications in the IR and UV-vis spectra of the samples.

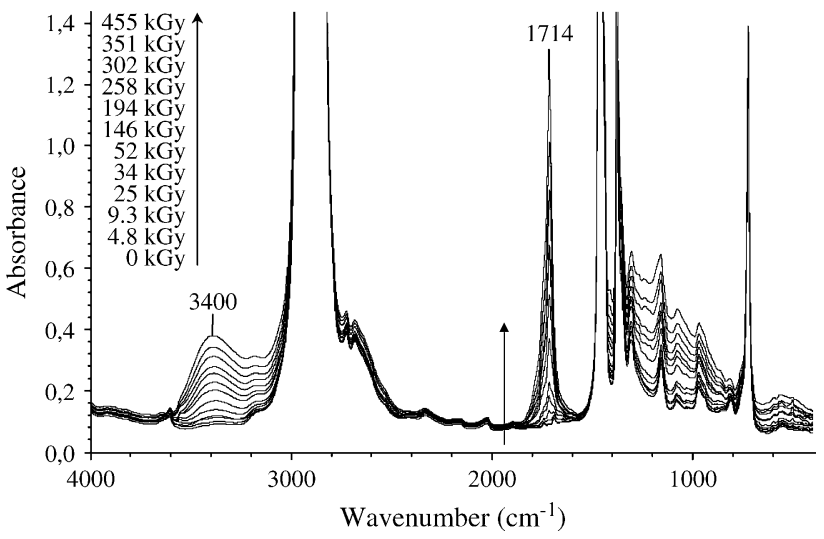

Fig. 1. IR spectral changes during $\gamma$-irradiation under oxygen atmosphere of additive-free EPDM 9 film.

The oxidation products formed by $\gamma$-irradiation of additive-free EPDM 9 were characterised by IR spectroscopy. The results obtained are shown in Fig. 1: the development of a broad band in the hydroxyl absorption region centred at $3400 \mathrm{~cm}^{-1}$ is observed and in the carbonyl region the formation of a carbonyl band with an absorption maximum at $1714 \mathrm{~cm}^{-1}$.

Focussing on these two regions of the FTIR region (see paper 2 [2]) showed several shoulders to the main absorption bands. This indicated that radio-oxidation produces a complex mixture of different products. The products were identified by combining IR analysis with chemical derivatisation reactions.

The maximum around $3400 \mathrm{~cm}^{-1}$ was attributed to hydrogen bonded $-\mathrm{OH}$ stretch of alcohols, hydroperoxides and carboxylic acids. The maxima at 3600 and $3553 \mathrm{~cm}^{-1}$ were, respectively, attributed to isolated $\mathrm{OH}$ stretch of alcohols and hydroperoxides. In parallel one observed a progressive decrease in the intensity of the $\nu(\mathrm{C}=\mathrm{H})$ absorption band at $3040 \mathrm{~cm}^{-1}$, which suggested the disappearance of the double bond of the termonomer ENB.

The appearance of a band with an absorption maximum at $1714 \mathrm{~cm}^{-1}$ accompanied by several shoulders around $1785,1755,1740$ and $1695 \mathrm{~cm}^{-1}$ was observed during radiooxidation. Saturated ketones $\left(1725-1718 \mathrm{~cm}^{-1}\right)$ and carboxylic acids $\left(1755\right.$ and $\left.1718-1710 \mathrm{~cm}^{-1}\right)$ were the main carbonyl products formed. The formation of esters $\left(1740 \mathrm{~cm}^{-1}\right)$ and $\gamma$-lactones $\left(1785 \mathrm{~cm}^{-1}\right)$ was shown to occur in lower concentrations. At weak conversion degree, unsaturated structures were observed to be formed: unsaturated ketones at $1685 \mathrm{~cm}^{-1}$ and unsaturated acids, identified by $\mathrm{SF}_{4}$ treatments, around $1700 \mathrm{~cm}^{-1}$.

In the region corresponding to the out of plane vibration of the $\mathrm{C}-\mathrm{H}$ bond linked to unsaturation, one observed a progressive decrease in the $\gamma(\mathrm{C}-\mathrm{H})$ absorbance at $808 \mathrm{~cm}^{-1}$, indicating therefore the progressive disappearance of the diene double bonds throughout radio-oxidation. 
The $\gamma$-irradiation of stabilised EPDM caused the same modification in the IR spectra as those observed for additive-free EPDM 9 but with a different rate. As an example, the change of the IR spectra of EPDM 12 is reported in Fig. 2.

The formation rates of carbonyl products measured at $1714 \mathrm{~cm}^{-1}$ and of hydroxyl products measured at $3400 \mathrm{~cm}^{-1}$ during $\gamma$-oxidation of EPDM are shown in Fig. 3A and B. The curves corresponding to the consumption of the double bond $\left(808 \mathrm{~cm}^{-1}\right)$ of the ENB as a function of the dose are plotted in Fig. 3C.

The kinetic curves given in Fig. 3 show that the curing has no effect on the oxidation and that the antioxidants do not prevent the oxidation of EPDM. It is only in the case of EPDM 12, cured and stabilised with Vulkanox at $1 \%$, that a stabilising effect can be observed, the rate of accumulation of the final oxidation products as well as the rate of consumption of the double bonds are reduced. A short induction period, before the oxidation starts is observed, below $25 \mathrm{kGy}$.

The EPDM 12 formulation has been studied in more detail because the high concentration of anti-oxidant used $(1 \%)$ permits the evaluation by IR spectroscopy of the stability of the additive.

Figs. $4 \mathrm{~A}$ and $5 \mathrm{~A}$ show the modifications of the spectra in the $\mathrm{C}=\mathrm{O}$ domain in the case of EPDM 12 and in the case of additive-free EPDM 9, limited to a dose of $52 \mathrm{kGy}$. In order to better characterise these modifications, the spectra obtained by subtraction of the initial spectrum from the spectra recorded after each irradiation dose are also presented (Figs. 4B and 5B).

Comparison of these figures shows that the envelope of the carbonyl absorption does not has the same shape for additive-free EPDM 9 and EPDM 12. It can be noted that the decrease in the double bond contents (absorption band at $1685 \mathrm{~cm}^{-1}$ ) occurs at a lower rate in the case of EPDM 12.

The formation of the oxidation products is accompanied by the consumption of the anti-oxidant as shown by

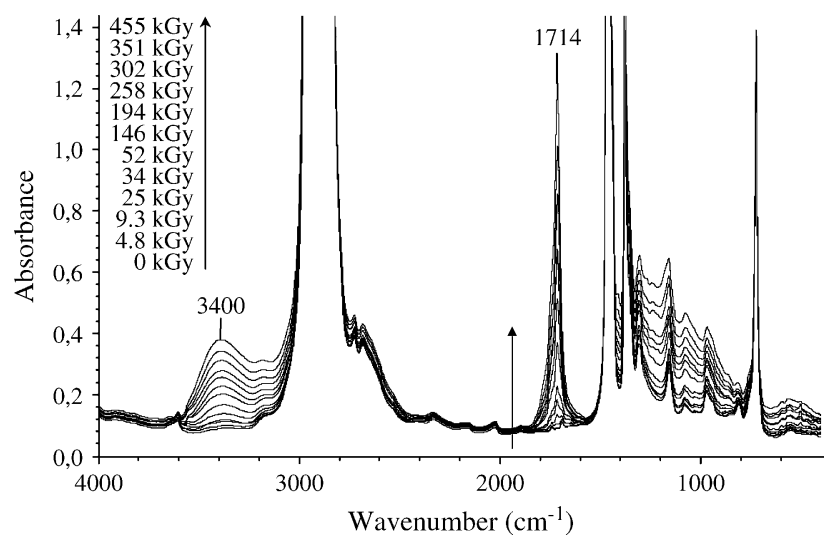

Fig. 2. IR spectral changes during $\gamma$-irradiation under oxygen atmosphere of EPDM 12 film.
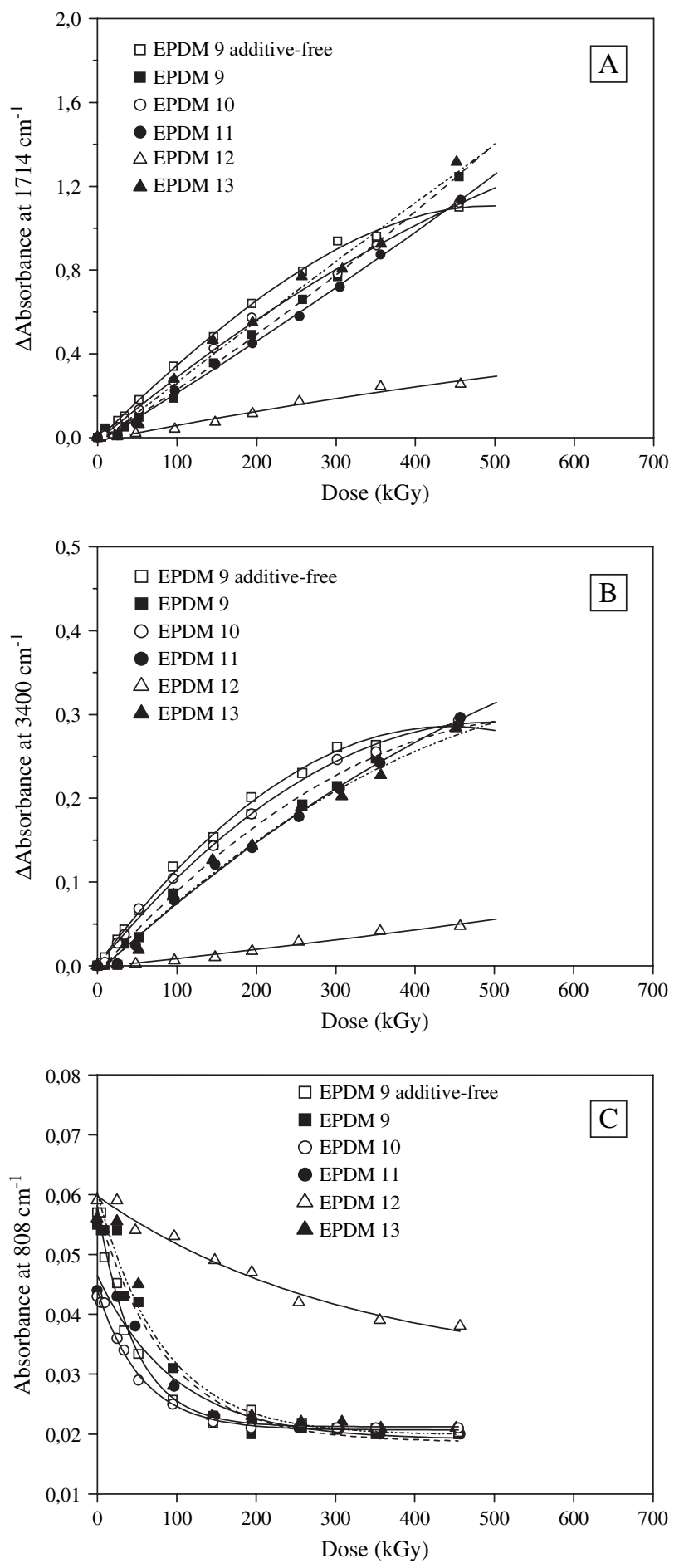

Fig. 3. Increase in the absorbance at 1714 (A) and $3400 \mathrm{~cm}^{-1}$ (B) as a function of the dose for various formulations of EPDM films $\gamma$-irradiated under oxygen atmosphere. (C) Decay in the absorbance at $808 \mathrm{~cm}^{-1}$ for various formulations of EPDM films $\gamma$-irradiated under oxygen atmosphere.

the progressive disappearance of the absorption bands at 1613, 1598, 1512 and $1496 \mathrm{~cm}^{-1}$. Fig. 6 shows the kinetic curves of oxidation and loss of additives in the case of EPDM 12. It can be observed that both the consumption 

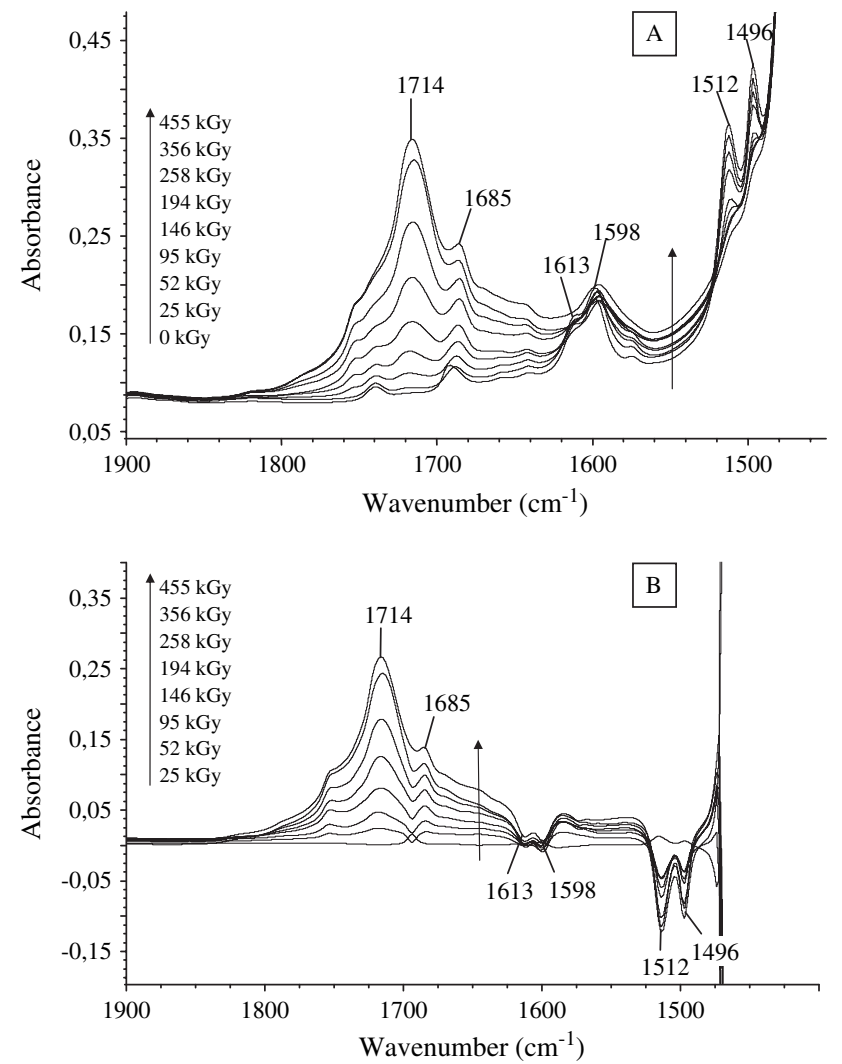

Fig. 4. IR spectral changes in $1900-1500 \mathrm{~cm}^{-1}$ region of EPDM 12 film $\gamma$-irradiated under oxygen atmosphere. (A) Direct spectra, (B) subtraction (irradiated - initial).

of the anti-oxidant and the formation of oxidative species are progressive all through the exposure.

Fig. 7 compares the rates of formation of the peroxide species (hydroperoxides and peroxides) for additive-free EPDM 9 and EPDM 12 films. The anti-oxidant is observed to be efficient in reducing the accumulation rate of peroxide species. A ratio of about 10 can be measured.

\subsection{Thermo-oxidation and photo-oxidation}

There are many similarities between the modifications of the IR spectra provoked by radio-, photo- and thermo-oxidation:

- The shapes of the hydroxyl absorption bands are the same in the three oxidative conditions. One observes the formation of an absorption band with a maximum centred at $3400 \mathrm{~cm}^{-1}$ accompanied by two shoulders around 3600 and $3553 \mathrm{~cm}^{-1}$.

- In the $1000-800 \mathrm{~cm}^{-1}$ region, the progressive decrease of the absorbance at $808 \mathrm{~cm}^{-1}$ indicates that the diene double bonds are saturated throughout oxidation.

- The carbonyl absorption bands that appear reveal the presence of the same maxima or shoulders as reported above at 1788,1732 and $1714 \mathrm{~cm}^{-1}$.
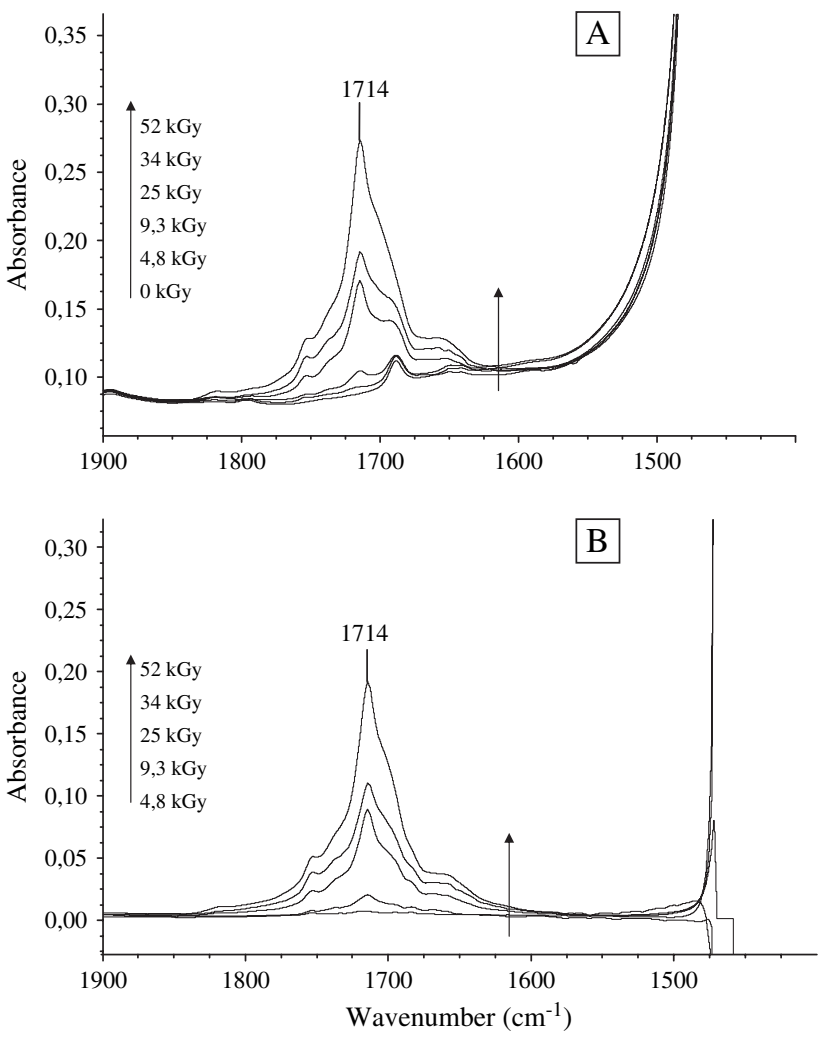

Fig. 5. IR spectral changes in $1900-1500 \mathrm{~cm}^{-1}$ region of additives-free EPDM 9 film $\gamma$-irradiated under oxygen atmosphere. (A) Direct spectra, (B) subtraction (irradiated - initial).

Ketones and carboxylic acids, responsible for the absorption maximum at $1714 \mathrm{~cm}^{-1}$, are the main oxidation products in the three conditions of ageing.

However, a detailed analysis shows that differences exist. First, the accumulation of esters $\left(1740 \mathrm{~cm}^{-1}\right)$ is favoured in thermo-oxidation, and photo-oxidation shows that high amounts of $\alpha, \beta$-unsaturated carbonyl groups (ketones and acids at $1685 \mathrm{~cm}^{-1}$ ) are formed.

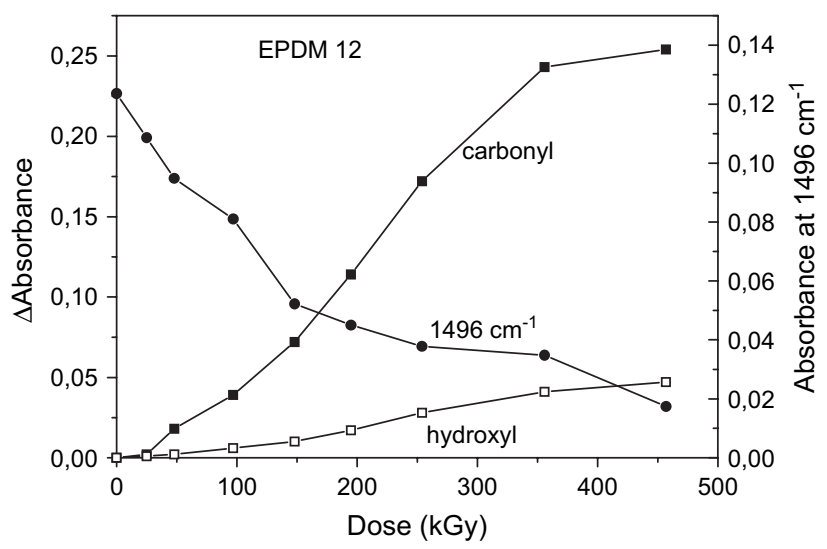

Fig. 6. Increase in the absorbance at 1714 and $3400 \mathrm{~cm}^{-1}$ and decay in the absorbance at $1496 \mathrm{~cm}^{-1}$ for EPDM 12 formulation of as a function of the dose. 


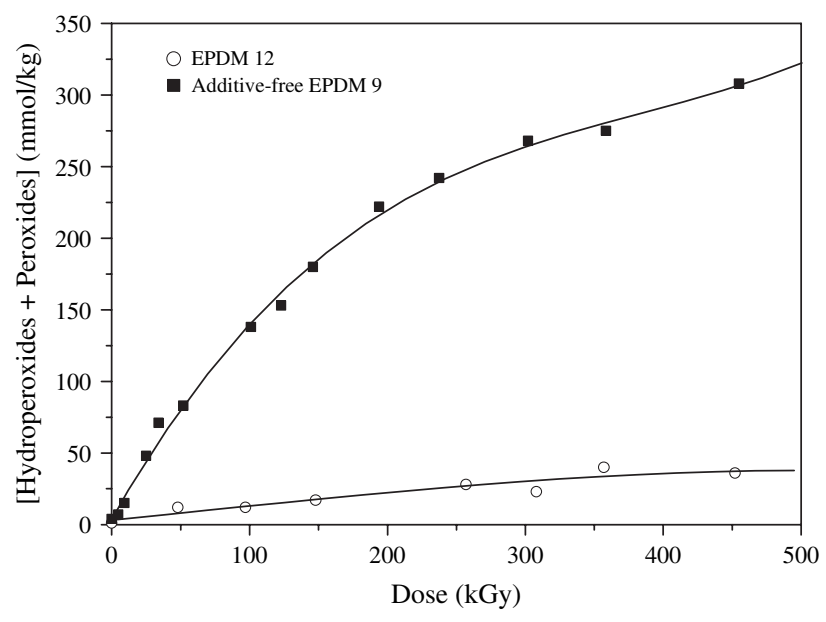

Fig. 7. Effect of the Vulkanox anti-oxidant on the peroxidic species concentration.

Second, when EPDM is stabilised by anti-oxidant or cross-linked, thermo-oxidation involves two steps:

- At low conversion one observes the development of a carbonyl absorption band centred at $1732 \mathrm{~cm}^{-1}$, whereas no hydroxyl groups and no maximum at $1714 \mathrm{~cm}^{-1}$ characteristic of the oxidation of the ethylene and propylene unit are formed and no consumption of the ENB double bonds is observed. This indicates that within the first period, it is the oxidation of the norbornene sites that occurs without attack of the double bonds (cross-linking).

- Then saturated ketones and carboxylic acids, responsible for the absorption at $1714 \mathrm{~cm}^{-1}$, rapidly become the main oxidation products. The formation of these products indicates the oxidation of ethylene and propylene units. During this second period, the double bonds disappear and hydroxyl groups are formed.

The formation rates of carbonyl products measured at $1714 \mathrm{~cm}^{-1}$ throughout thermo-oxidation of the various formulations are shown in Fig. 8.

From Fig. 8, it clearly appears that EPDM thermooxidation can be efficiently inhibited by anti-oxidants, with a notable induction period. Irganox and Vulkanox provide high stability. Cross-linking EPDM slightly decreases the efficiency of Irganox.

The formation rates of carbonyl products measured at $1714 \mathrm{~cm}^{-1}$ throughout photo-oxidation of the various formulations are shown in Fig. 9.

From curves drawn on Fig. 9, it is apparent that none of the additive systems causes a reduction in the formation rate of oxidation products. Some of the stabiliser systems even increase the initial rate of oxidation. If one gives a particular attention to the EPDM 12 formulation, it can be checked that the first

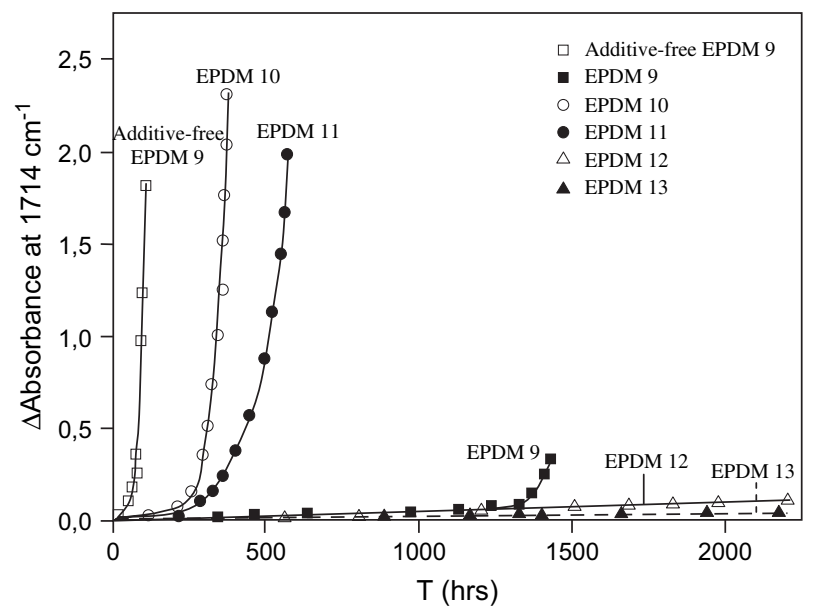

Fig. 8. Increase in the absorbance at $1714 \mathrm{~cm}^{-1}$ as a function of thermo-oxidation duration at $100{ }^{\circ} \mathrm{C}$ for various formulations of EPDM films.

five hours of exposure provoked the elimination of this anti-oxidant. This strongly suggests that the antioxidant photodegradation is likely to induce the polymer photo-oxidation.

\section{Discussion}

Oxidation of polymers induced by UV-light, temperature or $\gamma$-radiation results in chain scission, crosslinking and formation of oxygen-containing functional groups. The stabilisers role is to retard these oxidation processes. Oxidation prevention involves the scavenging of free-radical intermediates $\left(\mathrm{P}^{\bullet}\right.$ and $\mathrm{PO}_{2}^{*}$ radicals) and in some cases can also involve in the reduction of radicals formation.

Conventional anti-oxidants are highly efficient against EPDM thermal oxidation and provoke long

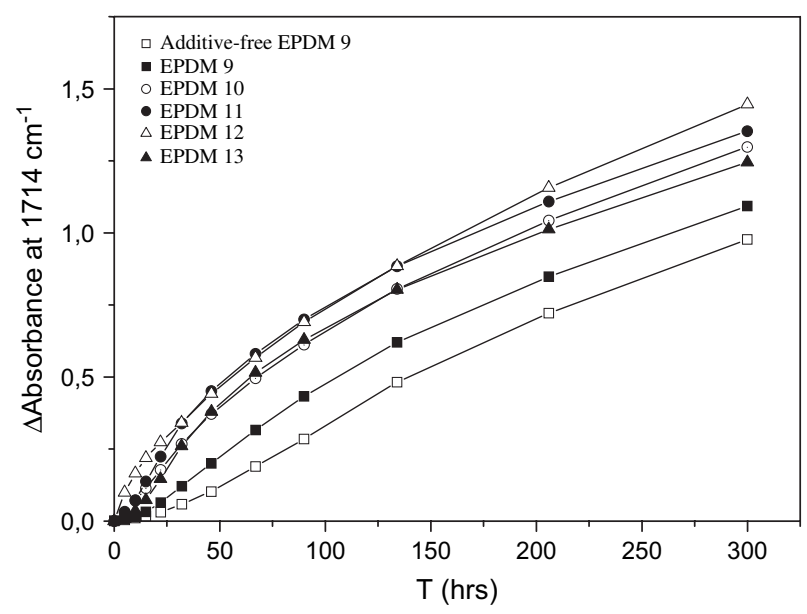

Fig. 9. Increase in the absorbance at $1714 \mathrm{~cm}^{-1}$ as a function of photooxidation duration for various formulations of EPDM films. 
induction periods. In the case of EPDM, the most oxidisable sites are the norbornene moieties. The oxidation of these groups is not easily inhibited by the anti-oxidants. However, oxidation of the norbornene sites has only minor consequences due to the low diene content $(0.7 \%$ diene $)$. Ethylene and propylene sites are less oxidisable than the norbornene units and the propagation of the chain oxidation reactions involving these units can be efficiently inhibited by anti-oxidant. The oxidation of EPDM is indeed strongly reduced in the case of EPDM 12 and EPDM 13 formulations.

In contrast, in condition of UV-light induced oxidation, anti-oxidants do not protect the polymer against oxidation. The inefficiency of the anti-oxidants results from two antagonist effects: due to their aromatic structure, anti-oxidants can absorb the incident UV light. The photochemical reactions which are in turn induced provoke the formation of radical species that are likely to initiate the polymer photo-oxidation by hydrogen abstraction from the macromolecular backbone. At the same time, anti-oxidants are likely to scavenge the $\mathrm{PO}^{*}$ and $\mathrm{POO}^{\circ}$ radicals which are formed. Their overall efficiency is the average of these two antagonistic effects, initiation of chain oxidation reactions and anti-oxidant effects. For these reasons, antioxidants must be protected by UV-absorbers in order to prevent them from absorbing UV-light [4,7].

Degradation of EPDM exposed to $\gamma$-rays was shown to result both from random direct radiation effects $(\mathrm{C}-\mathrm{H}$ scissions caused directly by radiation reaction) and from the selective oxidative chain reactions [3]. As the effect of high-energy radiation on matter results from random interaction with the electrons $[12,13]$, additives present in small concentrations do not directly absorb the energy. It was therefore expected that anti-oxidants would be stable and efficient to stop the chain oxidation process. Unfortunately, our results indicate that only the formulation based on Vulkanox shows a stabilising effect which is however very weak and with a very short induction period. In addition, the loss of the aromatic infrared absorption bands revealed degradation of the anti-oxidant. In order to understand the lack of efficiency of the anti-oxidants to protect EPDM against the $\gamma$-initiated oxidation, the following points have to be taken into account.

In the present experimental conditions, the rate formation of the oxidation products in additive-free EPDM 9 is about 10 times higher in thermo-oxidation than in $\gamma$-irradiation (compare Figs. $3 \mathrm{~A}$ and 8 , considering that the dose rate is $1 \mathrm{kGy} / \mathrm{h}$ ). This result is confirmed by the determination of the decomposition of hydroperoxides. For an EPDM film $\gamma$-irradiated at a $351 \mathrm{kGy}$ dose, a total disappearance of the hydroperoxides can be obtained only after $30 \mathrm{~h}$ of thermolysis at $100{ }^{\circ} \mathrm{C}$ whilst a $300 \mathrm{kGy}$ dose is not sufficient to provoke the decomposition of these products $[2,3]$.
- There are very strong differences between the initiation steps that are involved in the three ageing types: initiation is selective in thermo-oxidation and photo-oxidation, but statistical in $\gamma$-irradiation. The initiation step in $\gamma$-irradiation mainly involves the ethylene sites ( $77.9 \%$ ethylene). The concentration of radical species which are formed is largely too important to be stopped by the anti-oxidant even used at concentration $1 \%$.

- Another reason for the lack of efficiency of antioxidants results from the fact that they can be degraded during $\gamma$-irradiation, as observed by the loss of aromatic absorption bands. Part of this degradation is due to their anti-oxidant activity, which involves reactions with free-radicals intermediates. After hydrogen transfer to the peroxy radical, the phenoxy form of the anti-oxidant in the mesomeric form could give a quinone-type product [14-17]. But this proposal does not permit understanding the difference in efficiency between thermal and $\gamma$-oxidation. The anti-oxidants disappearance could also result from their degradation by the deposited energy, even if this interaction is not direct as in UV-degradation. Whilst thermooxidation and photo-oxidation only involves radical species, excited states and charged species such as ionic intermediates and electrons also account for $\gamma$-irradiation [18]. Aromatic rings are known to act as 'energy sinks' as they are able to trap charged species and quench the excited states [19]. Consequently to the excitation of the electrons of the macromolecular chains, transfer of the excitation energy (before scission of the main chain) to the aromatic additive may occur [20]. When the excitation energy is dissipated to heat, the additive constitutes a protecting agent ("anti-rad") able to prevent the radical formation resulting from direct radiation effects. In the EPDM case, energy transfer to additives is likely to be achieved, which results in the degradation of the chemical structure of the additive.

Results obtained with EPDM are in agreement with previous results obtained with polypropylene showing that the presence of residual "conventional" anti-oxidants induced the $\gamma$-degradation of the matrix [21].

As in the case of UV-degradation, an efficient stabilisation against $\gamma$-irradiation should take into account a rate of decrease in radical formation and should minimise the anti-oxidant degradation by the use of high concentration of aromatic molecules acting similarly with energy transfer and dissipation. Compounds like anthracene, biphenyl or aromatic polyimides, which were found to be effective "anti-rads" [22,23], should be used in combination with classical antioxidants. 


\section{Conclusion}

The oxidation rate of EPDM can be efficiently reduced by anti-oxidants in thermo-oxidation conditions. In photo-oxidation conditions, anti-oxidants can induce the EPDM degradation because they are not protected by UV-absorbers. In $\gamma$-irradiation conditions, anti-oxidants are rapidly consumed and only the aminetype formulation at $1 \%$ is observed to display a limited stability, with a very short induction period $(25 \mathrm{kGy})$ before the oxidation starts.

A more effective stabilisation system should involve the incorporation of two types of stabilisers in the polymer. For this purpose a parallel could be made between photo-oxidation and radio-oxidation. In photodegradation, a strong synergistic effect can be observed in the case of mixtures of UV-absorber and anti-oxidant. By analogy, a synergistic effect is expected between an "anti-rad" and an anti-oxidant. In the case of EPDM, fused-ring aromatics of anthracene-type (also called "anti-rads") could be added to the amine-type formulation. Whilst anti-oxidants are active on the propagation of the chain oxidation reactions, "antirads" are efficient against the initiation step. The effects of these stabilisers are thought to be an energy transfer of radiation from polymer to the aromatic compound, producing a delocalisation of the energy which is then changed to thermal energy. Meanwhile, the introduction of anti-oxidant and "anti-rad" could cause complex chemical reactions: the mixture of stabilisers could have synergistic effects or in contrast antagonism between the components could occur. Therefore, complementary studies have to be carried on.

\section{References}

[1] Rivaton A, Cambon S, Gardette JL. J Polymer Science Part A: Polymer Chemistry 2004;42:1239.
[2] Rivaton A, Cambon S, Gardette JL. Nuclear Instruments and Methods in Physical Research B 2004;227:343.

[3] Rivaton A, Cambon S, Gardette JL. Nuclear Instruments and Methods in Physical Research B 2004;227:357.

[4] Carlsson DJ, Dobbin CJB, Jensen JPT, Wiles DM. ACS Symposium Series 1985;280:359.

[5] Delor F, Teissedre G, Baba M, Lacoste J. Polymer Degradation and Stability 1999;60:321

[6] Coiffier F, Arnaud R, Lemaire J. Makromoleculare Chemie 1984;185:1095.

[7] Ranby B, Rabek JF. Photodegradation, photooxidation and photostabilization of coatings. New-York: Wiley-Interscience; 1975.

[8] Rivaton A. Polymer Degradation and Stability 1995;49:163.

[9] Piton M, Rivaton A. Polymer Degradation and Stability 1996; 53:343.

[10] Mair RD, Graupner A. Journal of Analytical Chemistry 1964;36:194.

[11] Gardette JL, Lemaire J. Polymer Photochemistry 1986;7:409.

[12] Charlesby A. Atomic radiation and polymers. Paris: Pergamon Press; 1960. p. 228.

[13] Partridge RH. Chemical Physics 1970;52:2501.

[14] Becker RF, Carlsson DJ, Cooke JM, Chmela S. Polymer Degradation and Stability 1988;22:313.

[15] Falicki S, Gosciniak DJ, Cooke JM, Cooney JD, Carlsson DJ. Polymer Degradation and Stability 1994;43:117.

[16] Thorat HB, Prabhu CS, Sureshkumar K, Pandya MV. Radiation Physics and Chemistry 1998;51:215.

[17] Mallegol J, Carlsson DJ, Deschenes L. Nuclear Instruments and Methods in Physical Research B 2001;185:283.

[18] Schnabel W. Polymer degradation, principles and practical applications. Munich: Carl Hanser Verlag; 1981.

[19] Clough R. Radiation-resistant polymers. In: Encyclopedia of polymer science and engineering, vol. 13. New York: John Wiley and Sons; 1988.

[20] Makhlis FA. Radiation physics and chemistry of polymers. Radiation protection of polymers. New York: Wiley; 1975 [chapter V].

[21] Rivaton A, Lalande D, Gardette JL. Nuclear Instruments and Methods in Physical Research B 2004;222:187.

[22] Soebianto YS, Kusuhata I, Katsumura Y, Ishiguro K, Kubo J, Koizumi H, et al. Polymer Degradation and Stability 1993; 42:29.

[23] Arakawa K, Seguchi T, Hayakawa N, Machi S. Journal of Polymer Science: Polymer Chemistry Edition 1983;21: 1173. 